\title{
Une greffe de moelle osseuse améliore les troubles neurologiques dans une enzymopathie de la souris
}

\section{Les nouvelles de ce numéro ont été préparées par : Jean-Claude Dreyfus Serge Erlinger Jean-Pierre Grüunfeld Axel Kahn}

Flash : Clonage du génome du virus hépatique non-A, non-B. Les hépatites secondaires au virus non-A, non-B constituent un redoutable probleme pour les transfusions sanguines puisque l'on ne savait pas détecter certainement cet agent. La firme Chiron vient d'isoler et de caractériser partiellement le génome d'un virus qui pourrait être responsable de la moitié des cas d'hépatites non-A, non-B. II s'agirait d'un virus à ARN simple brin de 10000 nucléotides appartenant au groupe des toga-virus.
Les retards psychomoteurs dus à des déficits en enzymes des lysosomes sont considérés comme incurables. La barrière hémo-méningée constitue en effet un obstacle majeur à la pénétration d'enzymes ou de cellules dans le système nerveux central à la suite d'une greffe. Ce pessimisme pourrait s'atténuer au vu de deux articles [1, 2] portant sur la souris twitcher. Cette souche présente à l'état homozygote un tremblement sévère et une paralysie du train postérieur entraînant la mort vers le $40^{\mathrm{e}}$ jour. C'est un modèle de la très grave maladie de Krabbe, ou leucodystrophie à cellules globoïdes chez l'homme. La lésion enzymatique est la même : un déficit en galactosylcéramidase, qui empêche la scission du galactose à partir d'un glycolipide appelé galactosylcéramide (formé d'une base, la sphingosine, d'un acide gras et de galactose); il s'accumule une galactosyl-sphingosine, la psychosine, toxique pour les cellules nerveuses. Il en résulte une démyélinisation massive.

Les deux équipes, comprenant des chercheurs néerlandais, américains et japonais, ont étudié l'effet des greffes de moelle chez les souris twitcher. Les animaux, encore cliniquement indemnes mais reconnus par l'absence de l'activité enzymatique, ont reçu vers le $10^{e}$ jour une greffe, congénique ou allogénique, de moelle osseuse provenant de souris saines. Les animaux greffés qui ont survécu avaient dans le cerveau un taux de galactosylcéramidase progressivement croissant; la concentration en psychosine se stabilisait à un niveau très inférieur à celui des témoins non greffés; enfin la myélinisation reprenait. Un fait capital, souligné par un des groupes [2], était la présence, après le premier mois, de macrophages spumeux, en même temps que diminuait le nombre des cellules globoïdes. Ces macrophages provenaient du donneur, comme on le prouvait aisément chez les souris qui avaient subi une greffe allogénique.

Ce travail démontre donc que des cellules du donneur, apportant l'enzyme qui manquait, sont capables, au moins dans le cas étudié, de pénétrer dans le système nerveux du receveur et de faire régresser en partie les lésions neurologiques. Il peut servir de point de départ à des tentatives thérapeutiques dans des maladies considérées jusqu'à présent comme inaccessibles à tout traitement. Les auteurs rappellent que, chez l'homme, une amélioration du développement psychomoteur a été décrite après greffe de moelle osseuse dans la leucodystrophie métachromatique [3, 4].

J.-C. D

1. Ichioka T, Kishimoto Y, Brennan S, Santos GW, Yeager AM. Hematopoietic cell transplantation in murine globoid celle leukodystrophy (the twitcher mouse). Proc Natl Acad Sci USA $1987 ; 84: 4259-63$.

2. Hoogerbrugge PM, Suzuki K, Suzuki K, et al. Donor-derived cells in the central nervous system of twitcher mice after bone marrow transplantation. Science 1988; 239 : 1035-8.

3. Bayever $\mathrm{E}$, Ladisch S, Philippart M, et al. Bone-marrow transplantation for metachromatic leucodystrophy. Lancet 1985 ; ii : $471-3$.

4. Krivit W, Lipton ME, Lockman IA, et al. Prevention of deterioration in metachromatic leukodystrophy by bone marrow transplantation. Am J Med Sci 1987 ; 294 : 80-5. 